\title{
Dietary supplementation with tributyrin alleviates intestinal injury in piglets challenged with intrarectal administration of acetic acid
}

\author{
Yongqing Hou ${ }^{1 *}$, Lei Wang ${ }^{1}$, Dan $\mathrm{Yi}^{1}$, Binying Ding ${ }^{1}$, Xing Chen ${ }^{1}$, Qingjing Wang ${ }^{1}$, Huiling Zhu ${ }^{1}$, \\ Yulan Liu ${ }^{1}$, Yulong Yin $^{1}$, Joshua Gong ${ }^{2}$ and Guoyao $\mathrm{Wu}^{3}$ \\ ${ }^{1}$ Hubei Key Laboratory of Animal Nutrition and Feed Science, Wuban Polytechnic University, Changqing Garden, \\ Wuhan 430023, Hubei, People's Republic of China \\ ${ }^{2}$ Guelph Food Research Centre, Agriculture and Agri-Food Canada, Guelph, Ontario, Canada N1G 5C9 \\ ${ }^{3}$ Department of Animal Science, Texas AGM University, College Station, TX 77843, USA
}

(Submitted 16 July 2013 - Final revision received 31 December 2013 - Accepted 6 January 2014 - First published online 10 February 2014)

\begin{abstract}
Tributyrin (TBU) is a good dietary source of butyrate and has beneficial effects on the maintenance of normal intestinal morphology. The present study tested the hypothesis that dietary TBU supplementation could alleviate intestinal injury in the acetic acid (ACA)-induced porcine model of colitis. A total of eighteen piglets $(25 \mathrm{~d}$ old $)$ were randomly allocated to one of three treatment groups (control, ACA and TBU). The control and ACA groups were fed a basal diet and the TBU group was fed the basal diet supplemented with $0 \cdot 1 \%$ TBU. On day 15 of the trial, under anaesthesia, a soft catheter was inserted into the rectum of piglets $(20-25 \mathrm{~cm}$ from the anus), followed by administration of either saline (control group) or ACA ( $10 \mathrm{ml}$ of $10 \%$ ACA solution for ACA and TBU groups). On day 22 of the trial, after venous blood samples were collected, piglets were killed to obtain mid-ileum and mid-colon mucosae. Compared with the control group, the ACA group exhibited an increase $(P<0.05)$ in lymphocyte counts, creatinine, $\mathrm{PGE}_{2}$, and malondialdehyde concentrations and diamine oxidase and inducible NO synthase activities in the plasma and lymphocyte density in the colon and a decrease in insulin concentrations and glutathione peroxidase activity, ileal villus height:crypt depth ratios and goblet cell numbers in the colon. These adverse effects of ACA were attenuated by TBU supplementation. Moreover, TBU prevented the ACA-induced increase in caspase-3 levels while enhancing claudin-1 protein and epidermal growth factor receptor (EGFR) mRNA expression in the colonic mucosa. Collectively, these results indicate that dietary supplementation with $0 \cdot 1 \%$ TBU alleviates ACA-induced intestinal injury possibly by inhibiting apoptosis, promoting tight-junction formation and activating EGFR signalling.
\end{abstract}

Key words: Tributyrin: Intestinal injury: Acetic acid: Colon: Piglets

Ulcerative colitis is a chronic inflammatory disease of the colon and rectum ${ }^{(1)}$. Recently, the inflamed colon has received attention in both humans and animals. Butyrate is an important energy substrate for mucosal cells of the large intestine and also plays an important role in the repair of the injured gut $^{(1,2)}$. As a normal constituent of the colonic luminal contents, butyrate is produced by the bacterial fermentation of unabsorbed complex carbohydrates in the mammalian digestive tract and of amino acids released from undigested proteins $^{(3)}$. In the normal colonic mucosa, butyrate serves as a primary energy source, promotes the growth of normal colonic epithelial cells and plays a role in the prevention of certain types of colitis ${ }^{(3,4)}$. By contrast, in a wide variety of neoplastic cells, butyrate has been reported to inhibit the growth of colonocytes in vitro ${ }^{(3,5,6)}$.

Normally, natural butyrate is largely absorbed in the stomach. Tributyrin (TBU), which is chemically synthesised from butyrate and $\mathrm{TAG}^{(3)}$, can bypass the stomach to reach the hind gut via oral administration ${ }^{(4-7)}$. TBU has beneficial effects on the attenuation of ulcerative colitis due to its trophic, anti-inflammatory, pro-apoptotic and anti-carcinogenic properties $^{(8)}$. Thus, TBU is a good dietary source of butyrate via the action of lipase in the intestine and has beneficial effects on the maintenance of normal intestinal morphology ${ }^{(2,9)}$. In support of this view, dietary supplementation with $5 \mathrm{~g} / \mathrm{kg}$ TBU has been shown to improve growth

Abbreviations: ACA, acetic acid; ADG, average daily weight gains; AR, amphiregulin; CAT, catalase; DAO, diamine oxidase; EGF, epidermal growth factor; EGFR, epidermal growth factor receptor; IEL, intraepithelial lymphocytes; iNOS, inducible nitric oxide synthase; MDA, malondialdehyde; OD, optical density; TBU, tributyrin.

*Corresponding author: Dr Y. Hou, fax +86 27 83956175, email houyq@aliyun.com 
performance and intestinal morphology in weanling pigs ${ }^{(2)}$. Additionally, TBU has positive effects on colonic restructuring in experimental colitis induced by dextran sodium sulphate in mice through the inhibition of inflammation and regulation of anti-inflammatory cytokine and regulatory T-cell expression ${ }^{(8)}$. Similarly, treatment of human mononuclear cells with butyrate, TBU, propionate or trichostatin $\mathrm{A}$ has been shown to inhibit TNF- $\alpha$ secretion and NF- $\kappa \mathrm{B}$ activation ${ }^{(10)}$. At present, little is known about the effects of TBU on ulcerative colitis in pigs.

Distal colitis in rats can be induced by intracolonic administration of acetic acid (ACA) ${ }^{(11,12)}$. This animal model shares many characteristics of human colitis ${ }^{(11,12)}$ to investigate the acute phase of inflammation ${ }^{(13-16)}$. Recently, a porcine model of colitis has been developed by intrarectal administration of $10 \% \mathrm{ACA}^{(11,17)}$. The disorder is characterised by a deregulation of the colonic mucosal immune system along with the presence of architectural distortion and infiltration of neutrophils and macrophages ${ }^{(17)}$. We hypothesised that dietary TBU supplementation could alleviate intestinal inflammation by reducing oxidative stress and activating epidermal growth factor receptor (EGFR) signalling. This hypothesis was tested in the present study using an ACA-induced porcine model of colitis.

\section{Materials and methods}

\section{Animal care and diets}

The animal use protocol followed in the present study was approved by the Animal Care and Use Committee of Hubei Province. A total of eighteen cross-bred healthy female piglets (Duroc $\times$ Landrace $\times$ Yorkshire) were reared by sows and then weaned at the age of $18 \mathrm{~d}$ to a maize and soyabean meal-based diet (Table 1), which was formulated to meet the National Research Council (1998)-recommended requirements for all nutrients. After a $7 \mathrm{~d}$ adaptation period, piglets ( $25 \mathrm{~d}$ of age and average body weight of 5.8 (SD 1.17) kg) were housed individually in stainless-steel metabolism cages $\left(1.20 \times 1.10 \mathrm{~m}^{2}\right)$ and maintained in an environmentally controlled room (at a room temperature of 28, 25 and $22^{\circ} \mathrm{C}$ during the first, second and third weeks of the trial, respectively). Each cage was equipped with a feeder and a nipple waterer to allow piglets free access to food and drinking-water.

\section{Experimental design}

At $25 \mathrm{~d}$ of age, piglets were randomly assigned to one of the following three treatment groups: (1) control group (nonchallenged control, piglets fed the basal diet and intrarectally administered with saline); (2) ACA group (ACA-challenged control, piglets fed the basal diet and intrarectally administered with ACA); (3) TBU group (ACA challenge + $0 \cdot 1 \%$ TBU, piglets fed the basal diet supplemented with $0 \cdot 1 \%$ TBU and intrarectally administered with ACA). There were six piglets per group. TBU (purity 97\%; Sigma) was mixed well with the basal diet. The diets of the control and ACA
Table 1. Ingredients and nutrient composition of the basal diet (air-dry basis)

\begin{tabular}{|c|c|}
\hline Items & Content \\
\hline \multicolumn{2}{|l|}{ Ingredients (\%) } \\
\hline Maize & $61 \cdot 88$ \\
\hline Soyabean meal & 21.98 \\
\hline Wheat middling & 4.00 \\
\hline Fishmeal & $3 \cdot 00$ \\
\hline Dried whey & $3 \cdot 00$ \\
\hline Soya protein concentrate & 1.50 \\
\hline $\mathrm{CaHPO}_{4}$ & $1 \cdot 25$ \\
\hline Premix $^{*}$ & 1.00 \\
\hline Limestone & 0.69 \\
\hline Soya oil & 0.50 \\
\hline Acidifier & $0 \cdot 30$ \\
\hline $\mathrm{NaCl}$ & $0 \cdot 30$ \\
\hline Mould inhibitor & $0 \cdot 10$ \\
\hline Choline chloride & $0 \cdot 20$ \\
\hline L-Lys.HCl (78.8 \% Lys) & $0 \cdot 25$ \\
\hline DL-Met (99\% Met) & 0.05 \\
\hline \multicolumn{2}{|l|}{ Nutrient composition } \\
\hline Digestible energy† (MJ/kg) & $14 \cdot 22$ \\
\hline Crude protein $(\%) \ddagger$ & $20 \cdot 90$ \\
\hline Total Lys (\%)† & $1 \cdot 15$ \\
\hline Total Met (\%)† & $0 \cdot 30$ \\
\hline Total Met + cystine (\%)† & 0.65 \\
\hline Total Thr (\%)† & 0.74 \\
\hline Total tryptophan (\%)† & $0 \cdot 21$ \\
\hline $\mathrm{Ca}(\%) \ddagger$ & $0 \cdot 70$ \\
\hline Total P (\%)‡ & 0.60 \\
\hline Available $\mathrm{P}(\%) \dagger$ & 0.32 \\
\hline \multicolumn{2}{|c|}{ 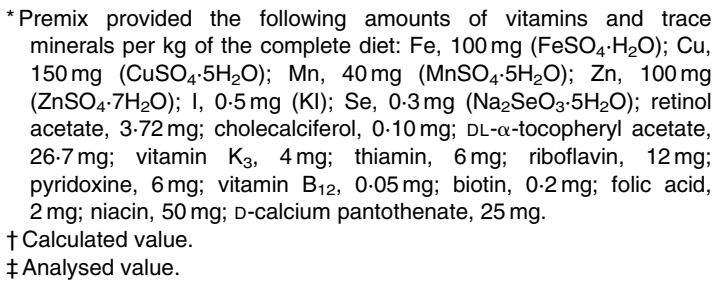 } \\
\hline
\end{tabular}

groups were supplemented with $0 \cdot 1 \%$ maize starch to obtain approximately isoenergetic diets. The dosage of supplemental TBU $(0 \cdot 1 \%)$ used in the study was chosen because it has been shown in previous studies that higher growth performance is achieved in pigs fed a diet supplemented with $0.1 \%$ sodium butyrate ${ }^{(18,19)}$. On day 15 of the trial, overnight fasted piglets in the ACA and TBU groups were intrarectally administered with ACA ( $10 \mathrm{ml}$ of $10 \%$ ACA), whereas piglets in the control group were intrarectally administered with the same volume of saline solution. Under anaesthesia (with an intravenous injection of sodium pentobarbital at a dose of $30 \mathrm{mg} / \mathrm{kg}$ body weight), a soft catheter was introduced into the rectum (20-25 cm from the anus) for careful administration of ACA or saline. Before removing the catheter, $20 \mathrm{ml}$ air was applied to spread ACA into the colon. During days $0-14$ of the trial (pre-challenge), all piglets had free access to food and drinking-water. To exclude a possible effect of ACA-induced reduction in food intake on the intestine of piglets, during days 15-21 of the trial (post-challenge with ACA), piglets in the control and TBU groups were pair-fed the same amount of feed per $\mathrm{kg}$ body weight fed to those in the ACA group. On day 22, all piglets were killed under 
anaesthesia with an intravenous injection of sodium pentobarbital ( $50 \mathrm{mg} / \mathrm{kg}$ body weight) to collect intestinal mucosae for further analysis.

\section{Blood sample collection}

On day 22 of the trial, blood samples were collected from the anterior vena cava into heparinised vacuum tubes (Becton Dickinson Vacutainer System), as described previously ${ }^{(20,21)}$. Blood samples $(7 \mathrm{ml})$ were centrifuged at $1000 \mathrm{~g}$ for $10 \mathrm{~min}$ at $4^{\circ} \mathrm{C}$ to separate plasma and then stored at $-80^{\circ} \mathrm{C}$ until analysis $^{(22,23)}$.

\section{Intestinal sample collection}

The abdomen of piglets was surgically opened immediately from the sternum to the pubis, and the whole gastrointestinal tract was immediately exposed ${ }^{(22,24)}$. The small intestine and colon were dissected free of the mesentery and placed on a chilled stainless-steel tray. Segments measuring 5 and $10 \mathrm{~cm}$ were cut from the mid-ileum and the mid-colon, respectively $^{(22,25)}$. The $5 \mathrm{~cm}$ intestinal segments were gently flushed with ice-cold PBS (pH 7.4) and then placed in 10\% fresh, chilled formalin solution for histological measurements ${ }^{(22,26)}$. The $10 \mathrm{~cm}$ intestinal segments were opened longitudinally and the contents were flushed with ice-cold $\mathrm{PBS}^{(21,22)}$. Mucosa was collected by scraping using a sterile glass microscope slide at $4^{\circ} \mathrm{C}^{(22,21,27)}$, rapidly frozen in liquid $\mathrm{N}_{2}$ and stored at $-80^{\circ} \mathrm{C}$ until analysis. All samples were collected within $15 \mathrm{~min}$ of killing.

\section{Determination of total and differential leucocyte counts}

Total and differential leucocyte counts were determined using an automated haematology analyser (Sysmex K4500, Sysmex Company). The differential leucocyte percentage was calculated as the ratio of leucocyte number:total leucocyte number ${ }^{(28)}$.

\section{Assessment of blood biochemical parameters}

Blood biochemical parameters (alanine aminotransferase, aspartate aminotransferase, blood urea $\mathrm{N}$ and creatinine) were assessed using an automatic analyser (7020 Clinical Analyzer, Hitachi High-Technologies Company).

\section{Determination of diamine oxidase activity in the plasma}

Diamine oxidase (DAO) activity in the plasma was determined using spectrophotometry as described by Hosoda et al. ${ }^{(29)}$. DAO was used as a marker of intestinal injury $^{(21,30)}$.

\section{Determination of growth-related hormone and $P G E_{2}$ concentrations in the plasma}

Growth hormone concentrations in the plasma were determined using a commercially available porcine growth hormone ${ }^{125}$ I RIA kit (Linco Research, Inc.). The minimum detection limit was $1 \mathrm{ng} / \mathrm{ml}$, with an intra-assay CV of $4.0 \%$.

Insulin-like growth factor-I concentrations in the plasma were determined using a commercially available porcine insulin-like growth factor-I IRMA kit (Diagnostic Systems Laboratories, Inc.). The minimum detection limit was $2 \mathrm{ng} / \mathrm{ml}$, with an intra-assay CV of $3.9 \%$.

Epidermal growth factor (EGF) concentrations in the plasma were determined using a commercially available ${ }^{125}$ I RIA kit (Beijing Sino-UK Institute of Biological Technology). Human EGF antibody was used as the standard, and the intra-assay and inter-assay $\mathrm{CV}$ were $<5$ and $<10 \%$, respectively. The detection limit was $0 \cdot 1 \mu \mathrm{g} / \mathrm{l}$.

Insulin concentrations in the plasma were determined using a commercially available ${ }^{125}$ I RIA kit (Beijing Sino-UK Institute of Biological Technology). The detection limit for the insulin assay was $13 \mathrm{pmol} / \mathrm{ml}$, with the intra-assay and inter-assay $\mathrm{CV}$ being $<10$ and $<15 \%$, respectively.

$\mathrm{PGE}_{2}$ concentrations in the plasma were determined using a commercially available ${ }^{125}$ I RIA kit (Beijing Sino-UK Institute of Biological Technology), which we had validated previously for pigs ${ }^{(31)}$. The detection limit for the $\mathrm{PGE}_{2}$ assay was $0 \cdot 12 \mathrm{pg} / \mathrm{ml}$. The intra-assay and inter-assay $\mathrm{CV}$ were $<7.5$ and $<10 \cdot 5 \%$, respectively.

\section{Determination of the activities of antioxidative enzymes and concentrations of their products in the plasma and colonic mucosa}

Plasma and colonic mucosa samples were used for the analysis of antioxidative enzymes and their products. Specifically, malondialdehyde (MDA), superoxide dismutase, catalase (CAT) and inducible NO synthase (iNOS) were analysed using commercially available kits (Nanjing Jiancheng Bioengineering Institute). Assays were carried out in triplicate ${ }^{(31)}$.

\section{Intestinal morphometric analyses}

Tissue samples used for the morphometric study were dehydrated and embedded in paraffin, sectioned at a thickness of $4 \mu \mathrm{m}$, and stained with haematoxylin and eosin ${ }^{(22,32)}$. Morphological measurements were carried out with a light microscope (American Optical Company). Ileal villus height and width, as well as crypt depth, were measured using a linear ocular micrometer equipped with a computer-assisted morphometric system (BioScan Optimetric, BioScan, Inc.). The villus height: crypt depth ratio and villous surface area were calculated. Colonic intraepithelial lymphocyte (IEL) number, lamina propria cell density and goblet cell number in crypts were determined $^{(26)}$. The number of IEL and goblet cells is expressed per 100 enterocytes. On the basis of cell morphology, differences among the nuclei of enterocytes, goblet cells and lymphocytes were clearly distinguishable at $400 \times$ magnification. Cell density was determined by counting total visibly stained nuclei and total lymphocytes in ten fields (total area of $4000 \mu \mathrm{m}^{2}$ ) from each section using a grid ocular. Cell density is expressed as the number of total stained cells and the number of lymphocytes per $1000 \mu \mathrm{m}^{2}$. The number 
of lymphocytes in relation to the number of total cells was also calculated. All morphometric analyses were carried out by the same person, who was blinded to the treatments, as described by Nofrarías et $a l{ }^{(26)}$.

\section{Determination of amphiregulin, epidermal growth factor} and epidermal growth factor receptor $m R N A$ levels using real-time $P C R$

Amphiregulin $(A R), E G F$ and EGFR mRNA levels in colonic mucosae were quantified using real-time PCR. Approximately $100 \mathrm{mg}$ of a frozen mucosal sample were powdered under liquid $\mathrm{N}_{2}$ using a mortar and pestle. The powdered samples were homogenised, and total RNA was isolated using the TRIzol Reagent protocol (Invitrogen). Total RNA was quantified using the NanoDrop ${ }^{\circledR}$ ND-2000 UV-VIS spectrophotometer (Thermo Scientific) at an optical density (OD) of $260 \mathrm{~nm}$, and the purity was assessed by determining the $\mathrm{OD}_{260}: \mathrm{OD}_{280}$ ratio. All samples had an $\mathrm{OD}_{260}: \mathrm{OD}_{280}$ ratio above $1 \cdot 8$, corresponding to $>95 \%$ pure nucleic acids. The integrity of RNA in each sample was assessed using $1 \%$ denatured agarose gel electrophoresis. RNA was used for real-time PCR analysis when it had a 28 S:18 S ribosomal RNA ratio $\geq 1 \cdot 8$.

Total RNA was reverse-transcribed using the PrimeScript ${ }^{\circledR}$ RT Reagent Kit with gDNA Eraser (Takara) according to the manufacturer's instructions. Complementary DNA was synthesised and stored at $-20^{\circ} \mathrm{C}$ until use. Real-time PCR analysis for the determination of gene expression was carried out using primers for $A R, E G F, E G F R$ and ribosomal protein L4 (RPL4) (Table 2) and the SYBR ${ }^{\circledR}$ Premix Ex Taq ${ }^{\mathrm{TM}}$ (Takara) on the Applied Biosystems 7500 Real-Time PCR System (Applied Biosystems, Inc.). The total volume of the PCR system was $50 \mu \mathrm{l}$. In brief, the reaction mixture contained $0 \cdot 2 \mu \mathrm{M}$ of each primer, $25 \mu \mathrm{l}$ of $\mathrm{SYBR}^{\circledR}$ Premix Ex $\mathrm{Taq}^{\mathrm{TM}}$ $(2 \times)$ and $4 \mu \mathrm{l}$ of complementary DNA in a $50 \mu \mathrm{l}$ reaction volume. All PCR were carried out in triplicate on a ninetysix-well real-time PCR plate (Applied Biosystems) under the following conditions (two-step amplification): $95^{\circ} \mathrm{C}$ for $30 \mathrm{~s}$, followed by forty cycles of $95^{\circ} \mathrm{C}$ for $3 \mathrm{~s}$ and $60^{\circ} \mathrm{C}$ for $30 \mathrm{~s}$. A subsequent melting curve analysis $\left(95^{\circ} \mathrm{C}\right.$ for $15 \mathrm{~s}, 60^{\circ} \mathrm{C}$ for

Table 2. Primers used for the real-time PCR analysis*

\begin{tabular}{|c|c|c|}
\hline Genes & & Primers \\
\hline \multirow[t]{2}{*}{$A R$} & Forward & $5^{\prime}$-GAGTACGATAACGAACCGCACA-3' \\
\hline & Reverse & $5^{\prime}$-TTTCCACTTTTGCCTCCCTTT- $3^{\prime}$ \\
\hline \multirow[t]{2}{*}{$E G F$} & Forward & $5^{\prime}$-TGCCATAAGGGTGTCAGGTATTT-3' \\
\hline & Reverse & 5'-TGCTTTGCTCTTGCCCTCTAC-3' \\
\hline \multirow[t]{2}{*}{$E G F R$} & Forward & 5'-GGCCTCCATGCTTTTGAGAA-3' \\
\hline & Reverse & 5'-GACGCTATGTCCAGGCCAA-3' \\
\hline \multirow[t]{2}{*}{ RPL4 } & Forward & 5'-GAGAAACCGTCGCCGAAT-3' \\
\hline & Reverse & 5'-GCCCACCAGGAGCAAGTT-3' \\
\hline
\end{tabular}

$A R$, amphiregulin; $E G F$, epidermal growth factor; $E G F R$, epidermal growth factor receptor; $R P L 4$, ribosomal protein $L 4$.

* The oligonucleotide primers were designed from pig gene sequences in the GenBank NM_214376 (for $A R$ ), NM_214020 (for EGF), NM-2140075 (for EGFR) and DQ845176 (for RPL4). To avoid amplification of potentially contaminating genomic DNA, the primers were designed to span introns and intron-exon boundaries.
$1 \mathrm{~min}$ and $95^{\circ} \mathrm{C}$ for $15 \mathrm{~s}$ ) with continuous fluorescence measurement and final cooling to room temperature was conducted. Amplification products were verified by melting curves and agarose gel electrophoresis. Results were analysed using the $\Delta \Delta C_{\mathrm{T}}$ method $^{(33)}$. The standard curves were generated using relative concentration $v . C_{\mathrm{T}}$ value. The linear correlation coefficients of all genes were $>0.995$. Based on the slopes of the standard curves, the amplification efficiencies of the standard ranged from 90 to $110 \%$ (derived from the formula efficiency $\left.=10^{1 /- \text { slope }}-1\right)^{(34)}$. Moreover, we tested other housekeeping genes (GAPDH and $\beta$-actin) by analysing gene stability as described by Vandesompele et al. $^{(35)}$ and found the expression of RPL4 to be more stable than that of other housekeeping genes in the colonic mucosa; therefore, we used RPL4 as the normaliser in the calculation of relative mRNA levels for target genes. Each biological sample was run in triplicate.

\section{Protein immunoblot analysis}

Caspase- 3 and claudin-1 proteins were analysed by Western blot analysis as described by Hou et al. ${ }^{(21)}$. Briefly, frozen intestinal mucosal samples were powdered under liquid $\mathrm{N}_{2}$ using a mortar and pestle. The powdered samples $(100 \mathrm{mg})$ were homogenised in $1 \mathrm{ml}$ of lysis buffer using a Polytron homogeniser. The homogenates were centrifuged at $12000 \mathrm{~g}$ for $15 \mathrm{~min}$ at $4^{\circ} \mathrm{C}$. The supernatant fluid was aliquoted into microcentrifuge tubes, to which $2 \times$ SDS sample buffer ( $2 \mathrm{ml}$ of $0.5 \mathrm{~mol} / 1$ Tris, $\mathrm{pH} 6.8,2 \mathrm{ml}$ glycerol, $2 \mathrm{ml}$ of $10 \%$ SDS, $0.2 \mathrm{ml}$ of $\beta$-mercaptoethanol, $0.4 \mathrm{ml}$ of a $4 \%$ solution of bromophenol blue and $1.4 \mathrm{ml}$ of water) was added at a ratio of $1: 1$. The samples were boiled for $5 \mathrm{~min}$ and cooled on ice before being used for Western blot analysis. Proteins ( $150 \mu \mathrm{g} / \mathrm{sample}$ for caspase-3; $60 \mu \mathrm{g} / \mathrm{sample}$ for claudin-1 and $\beta$-actin) were separated by electrophoresis on a $10 \%$ (for caspase- 3 and $\beta$-actin) or $12 \%$ (for claudin-1) polyacrylamide gel. Proteins were electrophoretically transferred onto polyvinylidene difluoride membranes. Non-fat dry milk in TBS $\mathrm{T}$ buffer was used to block the membranes for at least $1 \mathrm{~h}$ at room temperature. The membranes were incubated with primary antibodies overnight at $4^{\circ} \mathrm{C}$ : caspase-3 (rabbit polyclonal antibodies from Cell Signaling Technology, Inc.; dilution 1:1000); claudin-1 (rabbit monoclonal antibodies from Invitrogen Technology, Inc.; dilution 1:1000); $\beta$-actin (mouse monoclonal antibodies from sigma Chemicals; dilution 1:5000). The primary antibody dilution buffer was $1 \times$ TBS-0.1\% Tween 20 with $5 \%$ bovine serum albumin. The membranes were washed three times with TBS T $(1 \times$ Tris-buffered saline including $0 \cdot 1 \%$ Tween 20) and incubated for $1 \mathrm{~h}$ at room temperature with anti-rabbit (mouse) IgG horseradish peroxidase-conjugated secondary antibodies (Beijing ZhongShan Golden Bridge Biological Technology Company, Limited; dissolved in 5\% non-fat dry milk in TBS-Tween 20 buffer at 1:5000 dilution). The incubation of membranes with primary antibodies was followed by three washes with TBS $\mathrm{T}$ buffer for $10 \mathrm{~min}$, and incubation with secondary antibodies was followed by five washes for $8 \mathrm{~min}$. Blots were developed using an Enhanced Chemiluminescence 
Western blotting kit (ECL-plus, Amersham Biosciences), visualised and quantified using an imaging system (Alpha Innotech FluorChem FC2).

\section{Statistical analyses}

Results are expressed as means and standard deviations of the means with their standard errors and statistically analysed by one-way ANOVA. The normality and constant variance of the experimental data were tested using Levene's test ${ }^{(36)}$. If data did not have homogeneous variance, they were log-transformed to meet the necessary assumptions for ANOVA $^{(36)}$. Differences among the treatment means were determined using Duncan's multiple range tests. All statistical analyses were carried out using the SPSS 13.0 software (SPSS, Inc.). $P$ values $<0.05$ were considered to indicate statistical significance, and $P$ values $<0 \cdot 1$ were considered as trends towards statistical significance.

\section{Results}

\section{Effects of dietary tributyrin supplementation on the growth performance of piglets}

Between days 0 and 14 of the trial (before the ACA challenge), average daily feed intakes of piglets were 554,540 and $551 \mathrm{~g} / \mathrm{d}$ $(P=0 \cdot 804)$, average daily weight gains (ADG) were 314, 322 and $373 \mathrm{~g} / \mathrm{d}(P=0.090)$, and feed:gain ratios were $1.7,1.7$ and $1.5(P=0.096)$, respectively, in the control, ACA and TBU groups. Dietary TBU supplementation tended to $(P<0 \cdot 1)$ increase ADG and decrease feed:gain ratios. Between days 15 and 21 of the trial (the ACA challenge period), average daily feed intakes of piglets were 574, 577 and $576(P=0 \cdot 205)$, ADG were 306, 261 and $284 \mathrm{~g} / \mathrm{d}(P=0.439)$, and feed:gain ratios were $1 \cdot 9,2 \cdot 2$ and $2 \cdot 1(P=0 \cdot 425)$, respectively, in the control, ACA and TBU groups.

Effects of dietary tributyrin supplementation on total and differential leucocyte counts, erythrocyte counts and $\mathrm{Hb}$ concentrations in piglets after the acetic acid challenge

The ACA group had higher $(P<0.05)$ leucocyte, lymphocyte and neutrophil counts than the control group (Table 3). In comparison with piglets in the ACA group, those in the TBU group had lower lymphocyte counts $(P<0.05)$, without any change in leucocyte and neutrophil counts. Erythrocyte counts, $\mathrm{Hb}$ concentrations and lymphocyte percentage in the blood did not differ among the treatment groups.

\section{Effects of dietary tributyrin supplementation on the blood} biochemical parameters of piglets after the acetic acid challenge

The average mean values for alanine aminotransferase in the plasma were $52 \cdot 2,51 \cdot 2$ and $54 \cdot 3 \mathrm{U} / 1(P=0 \cdot 414)$, for aspartate aminotransferase $35 \cdot 2,40 \cdot 3$ and $35.6 \mathrm{U} / 1 \quad(P=0 \cdot 422)$, for blood urea N 2.4, $2 \cdot 6$ and $2 \cdot 9 \mathrm{mmol} / \mathrm{l}(P=0.265)$, and for creatinine $73.9,82.8$ and $78.8 \mu \mathrm{mol} / 1(P=0.005)$, respectively, in
Table 3. Total and differential leucocyte counts, erythrocyte counts and $\mathrm{Hb}$ concentrations in the blood of piglets

(Mean values with their standard errors, $n 6$ )

\begin{tabular}{|c|c|c|c|c|c|}
\hline Items & Control* $^{*}$ & ACA† & TBU‡ & $\begin{array}{l}\text { Pooled } \\
\text { SEM }\end{array}$ & $P$ \\
\hline $\begin{array}{c}\text { Leucocytes } \\
\left(10^{6} / \mathrm{ml}\right)\end{array}$ & $12 \cdot 4^{a}$ & $17 \cdot 4^{b}$ & $16 \cdot 6^{\mathrm{b}}$ & 1.67 & 0.021 \\
\hline $\begin{array}{l}\text { Erythrocytes } \\
\left(10^{9} / \mathrm{ml}\right)\end{array}$ & $5 \cdot 69$ & $5 \cdot 84$ & $5 \cdot 81$ & 0.162 & 0.610 \\
\hline $\mathrm{Hb}(\mathrm{g} / \mathrm{l})$ & $103 \cdot 8$ & $103 \cdot 5$ & $97 \cdot 9$ & 3.14 & 0.151 \\
\hline $\begin{array}{l}\text { Lymphocyte } \\
\text { percentage (\%) }\end{array}$ & $59 \cdot 2$ & $58 \cdot 2$ & $49 \cdot 9$ & 0.05 & 0.124 \\
\hline $\begin{array}{l}\text { Lymphocytes } \\
\left(10^{6} / \mathrm{ml}\right)\end{array}$ & $6 \cdot 9^{a}$ & $10 \cdot 4^{b}$ & $7 \cdot 1^{a}$ & 1.32 & 0.034 \\
\hline $\begin{array}{l}\text { Neutrophils } \\
\left(10^{6} / \mathrm{ml}\right)\end{array}$ & $4 \cdot 77^{a}$ & $6 \cdot 24^{b}$ & $7 \cdot 74^{\mathrm{b}}$ & $0 \cdot 771$ & 0.004 \\
\hline
\end{tabular}

ACA, acetic acid; TBU, tributyrin.

a,b Mean values within a row with unlike superscript letters were significantly different $(P<0.05)$.

*Non-challenged control: piglets fed the basal diet and intrarectally administered with saline.

†ACA-challenged control: piglets fed the basal diet and intrarectally administered with ACA.

$\ddagger$ ACA challenge $+0.1 \%$ TBU supplementation: piglets fed the basal diet supplemented with $0.1 \% \mathrm{TBU}$ and intrarectally administered with ACA.

the control, ACA and TBU groups. $(1 \mathrm{u} / 1$ is defined as the amount of alanine aminotransferase or aspartate aminotransferase required for catalysing $1 \mu \mathrm{mol}$ of $\alpha$-Ketoglutarate $/ \mathrm{min}$ per litre plasma at $\left.25^{\circ} \mathrm{C}\right)$. Compared with the control group, the ACA group exhibited an increase $(P<0.05)$ in creatinine concentrations in the plasma. Relative to the ACA group, the TBU group exhibited a decrease $(P<0 \cdot 1)$ in creatinine concentrations in the plasma.

Effects of dietary tributyrin supplementation on growth hormone, insulin-like growth factor-I, epidermal growth factor, insulin and $P G E_{2}$ concentrations in the plasma of piglets

Compared with the control group, the ACA group exhibited an increase $(P<0.05)$ in $\mathrm{PGE}_{2}$ concentrations in the plasma. In comparison with the ACA group, the TBU group exhibited an increase $(P<0.05)$ in insulin concentrations, but a decrease $(P<0 \cdot 1)$ in $\mathrm{PGE}_{2}$ concentrations in the plasma (Table 4).

Effects of dietary tributyrin supplementation on redox status in the plasma and colonic mucosa of piglets after the acetic acid challenge

Data on the concentrations of antioxidative enzymes and related products in the plasma and colonic mucosae are summarised in Table 5. Compared with the control group, the ACA group exhibited an increase $(P<0.05)$ in MDA concentrations and iNOS activity in the plasma. In comparison with the ACA group, the TBU group exhibited a decrease $(P<0.05)$ in MDA concentrations and iNOS activity in the plasma. 
Table 4. Growth hormone (GH), insulin-like growth factor (IGF)-I, epidermal growth factor (EGF), insulin and $\mathrm{PGE}_{2}$ concentrations in the plasma of piglets

(Mean values with their standard errors, $n 6$ )

\begin{tabular}{lccccc}
\hline Items & Control $^{*}$ & ACA & TBU & Pooled SEM & $P$ \\
\hline GH $(\mathrm{pg} / \mathrm{ml})$ & 4.87 & 4.80 & 4.34 & 0.357 & 0.308 \\
IGF-I $(\mathrm{ng} / \mathrm{ml})$ & 156 & 154 & 156 & 13.8 & 0.994 \\
EGF $(\mathrm{ng} / \mathrm{ml})$ & 0.72 & 0.92 & 0.88 & 0.123 & 0.261 \\
Insulin $(\mathrm{pmol} / \mathrm{l})$ & $111.7^{\mathrm{a}, \mathrm{b}}$ & $92.0^{\mathrm{a}}$ & $120.0^{\mathrm{b}}$ & 10.31 & 0.082 \\
PGE $_{2}(\mathrm{pg} / \mathrm{ml})$ & $32.7^{\mathrm{a}}$ & $35.4^{\mathrm{b}}$ & $33.7^{\mathrm{a}, \mathrm{b}}$ & 1.15 & 0.089 \\
\hline
\end{tabular}

ACA, acetic acid; TBU, tributyrin.

${ }^{a, b}$ Mean values within a row with unlike superscript were letters significantly different $(P<0.05)$

${ }^{*}$ Non-challenged control: piglets fed the basal diet and intrarectally administered with saline.

†ACA-challenged control: piglets fed the basal diet and intrarectally administered with ACA.

$\ddagger$ ACA challenge $+0.1 \%$ TBU supplementation: piglets fed the basal diet supplemented with $0.1 \%$ TBU and intrarectally administered with ACA.

Compared with the control group, the ACA group exhibited an increase $(P<0.05)$ in MDA concentrations and a decrease $(P<0.05)$ in CAT activity in the colonic mucosa. However, MDA concentrations and CAT activities in the colonic mucosa did not differ between the ACA and TBU groups.

\section{Effects of dietary tributyrin supplementation on plasma} diamine oxidase activity in piglets after the acetic acid challenge

Data on DAO activity in the plasma are summarised in Table 5. Compared with the control group, the ACA group exhibited an increase $(P<0.05)$ in DAO activity in the plasma. In comparison with the ACA group, the TBU group exhibited a decrease $(P<0.05)$ in DAO activity in the plasma.
Effects of dietary tributyrin supplementation on the intestinal mucosal histomorphology of piglets after the acetic acid challenge

Morphometric measurements are summarised in Table 6. Compared with the control group, the ACA group exhibited a decrease $(P<0.05)$ in the ratio of villus height:crypt depth in the ileum. In comparison with the ACA group, the TBU group exhibited an increase $(P<0 \cdot 1)$ in the ratio of villus height:crypt depth in the ileum and in the number of goblet cells per 100 enterocytes in the colon, but a decrease $(P<0.05)$ in the number of IEL per 100 enterocytes and lymphocyte density in the colon. Morphometric measurements in the duodenum and jejunum did not differ among the control, ACA and TBU groups (data not shown). Compared with the control group, the ACA group exhibited a decrease $(P<0.05)$ in the number of goblet cells per 100 enterocytes and an increase $(P<0.05)$ in the number of IEL per 100 enterocytes and lymphocyte density in the colon.

The colonic mucosa of the ACA group exhibited ulcerations and obvious infiltration by inflammatory cells (Fig. 1). The histological ulcers revealed necrosis in the colonic mucosa with submucosal inflammation, with neutrophils and lymphocytes as the predominant infiltrating cells. Collectively, some adverse effects of ACA were attenuated by dietary supplementation with $0 \cdot 1 \%$ TBU

\section{Effects of dietary tributyrin supplementation on amphiregulin, epidermal growth factor and epidermal growth factor receptor $m R N A$ levels in the colonic mucosa of piglets after the acetic acid challenge}

Data on $A R, E G F$ and EGFR mRNA levels in the colonic mucosa are summarised in Table 7. Mucosal EGFR mRNA

Table 5. Diamine oxidase (DAO) activity in the plasma as well as the redox status in the plasma and colonic mucosa of piglets

(Mean values with their standard errors, $n 6$ )

\begin{tabular}{|c|c|c|c|c|c|}
\hline Items & Control* $^{*}$ & ACA† & TBU & Pooled SEM & $P$ \\
\hline \multicolumn{6}{|l|}{ Plasma } \\
\hline DAO $(\mathrm{U} / \mathrm{ml}) \S$ & $0.34^{\mathrm{a}}$ & $0.65^{\mathrm{b}}$ & $0.43^{\mathrm{a}}$ & 0.086 & 0.019 \\
\hline MDA (nmol/mg protein) & $5 \cdot 30^{\mathrm{a}}$ & $7.02^{b}$ & $5 \cdot 43^{\mathrm{a}}$ & 0.439 & 0.002 \\
\hline SOD $(U / m l) \S$ & $52 \cdot 9$ & $52 \cdot 1$ & 47.4 & $6 \cdot 72$ & 0.138 \\
\hline CAT $(\mathrm{U} / \mathrm{ml}) \S$ & $3 \cdot 24$ & 3.32 & $2 \cdot 63$ & 0.773 & 0.436 \\
\hline iNOS (U/ml)§ & $10 \cdot 1^{a}$ & $13 \cdot 1^{b}$ & $10 \cdot 7^{a}$ & 0.78 & 0.004 \\
\hline \multicolumn{6}{|l|}{ Colonic mucosa } \\
\hline MDA (nmol/mg protein) & $0.31^{\mathrm{a}}$ & $0.48^{\mathrm{b}}$ & $0.42^{\mathrm{a}, \mathrm{b}}$ & 0.071 & 0.080 \\
\hline SOD (U/mg protein)\| & $19 \cdot 8$ & $24 \cdot 3$ & $21 \cdot 6$ & $3 \cdot 17$ & 0.381 \\
\hline CAT (U/mg protein)\| & $1 \cdot 11^{b}$ & $0.95^{\mathrm{a}}$ & $0.90^{\mathrm{a}}$ & 0.075 & 0.043 \\
\hline iNOS (U/mg protein)\| & 0.92 & 0.80 & 0.83 & $0 \cdot 101$ & 0.509 \\
\hline
\end{tabular}

ACA, acetic acid; TBU, tributyrin; MDA, malondialdehyde; SOD, superoxide dismutase; CAT, catalase; iNOS, inducible NO synthase.

a,b Mean values within a row with unlike superscript letters were significantly different $(P<0.05)$.

${ }^{*}$ Non-challenged control: piglets fed the basal diet and intrarectally administered with saline.

†ACA-challenged control: piglets fed the basal diet and intrarectally administered with ACA.

$\ddagger A C A$ challenge $+0.1 \%$ TBU supplementation: piglets fed the basal diet supplemented with $0.1 \%$ TBU and intrarectally administered with ACA.

$\S 1 \mathrm{U} / \mathrm{ml}$ is defined as the amount of DAO, SOD, CAT or iNOS required for catalysing $1 \mathrm{mmol}$ of cadaverine dihydrochloride, superoxide $\left(\mathrm{O}^{2-}\right), \mathrm{H}_{2} \mathrm{O}_{2}$ or L-arginine/min per $\mathrm{ml}$ plasma at $25^{\circ} \mathrm{C}$, respectively.

$\| 1 \mathrm{U} / \mathrm{mg}$ (colon SOD, CAT and iNOS) is defined as the amount of SOD, CAT or iNOS required for catalysing $1 \mathrm{mmol}$ of $\mathrm{O}^{2-}, \mathrm{H}_{2} \mathrm{O}_{2}$ or L-arginine/min per $\mathrm{mg}$ colon protein at $25^{\circ} \mathrm{C}$, respectively. 
Table 6. Intestinal mucosal histomorphology of piglets after the acetic acid (ACA) challenge (Mean values with their standard errors, $n 6$ )

\begin{tabular}{lccccc}
\hline Items & Control $^{*}$ & ACA $\dagger$ & TBU $\ddagger$ & Pooled SEM & $P$ \\
\hline Ileum & & & & & \\
$\quad$ Villus height $(\mu \mathrm{m})$ & 246 & 221 & 231 & 32.6 & 0.741 \\
Crypt depth $(\mu \mathrm{m})$ & 61 & 69 & 61 & 6.0 & 0.306 \\
Villus height:crypt depth ratio & $4.0^{\mathrm{b}}$ & $3.2^{\mathrm{a}}$ & $3.8^{\mathrm{a}, \mathrm{b}}$ & 0.36 & 0.078 \\
$\quad$ Villous surface area $\left(\mathrm{cm}^{2}\right)$ & 2.5 & $2 \cdot 3$ & 2.5 & 0.56 & 0.812 \\
Colon & & & & & \\
Crypt depth $(\mu \mathrm{m})$ & 193 & 202 & 216 & 17.0 & 0.388 \\
Goblet cells/100 enterocytes & $10.0^{\mathrm{b}}$ & $7.6^{\mathrm{a}}$ & $9.5^{\mathrm{a}, \mathrm{b}}$ & 0.94 & 0.054 \\
IEL/100 enterocytes & $1.5^{\mathrm{a}}$ & $2 \cdot 9^{\mathrm{b}}$ & $1.9^{\mathrm{a}}$ & 0.30 & 0.001 \\
Cell density & 1.3 & 0.9 & 1.1 & 0.18 & 0.138 \\
Lymphocyte density & $1.6^{\mathrm{a}}$ & $2.4^{\mathrm{b}}$ & $1.2^{\mathrm{a}}$ & 0.25 & 0.001 \\
\hline
\end{tabular}

TBU, tributyrin; IEL, intraepithelial lymphocytes.

a,b Mean values within a row with unlike superscript letters were significantly different $(P<0.05)$

* Non-challenged control: piglets fed the basal diet and intrarectally administered with saline.

†ACA-challenged control: piglets fed the basal diet and intrarectally administered with ACA.

$\ddagger$ ACA challenge $+0.1 \%$ TBU supplementation: piglets fed the basal diet supplemented with $0.1 \%$ TBU and intrarectally administered with ACA.

levels were lower $(P<0.05)$ in the colonic mucosa $(-26 \%)$ of ACA piglets than in that of the control piglets. Compared with the ACA group, the TBU group exhibited an increase $(P<0.05)$ in the abundance of EGFR mRNA in the colonic mucosa by $59 \%$. No differences in $A R$ or $E G F$ mRNA levels were detected in the colonic mucosa among the treatment groups.

Effects of dietary tributyrin supplementation on the abundance of caspase-3 and claudin-1 proteins in the colonic mucosa of piglets after the acetic acid challenge

The ACA group exhibited an increase $(P<0.05)$ in the abundance of caspase- 3 protein and a decrease $(P<0.05)$ in that of claudin-1 protein in the colonic mucosa compared with the control group. Relative to the ACA group, the TBU group exhibited a decrease $(P<0.05)$ in caspase-3 expression and an increase $(P<0.05)$ in claudin-1 expression in the colonic mucosa (Figs. 2 and 3). The levels of caspase-3 and claudin-1 in TBU-supplemented piglets were comparable to those of the control group.

\section{Discussion}

ACA-induced colitis in rats shares many characteristics with the human disease ${ }^{(11,12)}$, and similar studies involving other models and other species have been reported ${ }^{(11,37)}$. To our knowledge, the present study is the first to determine the

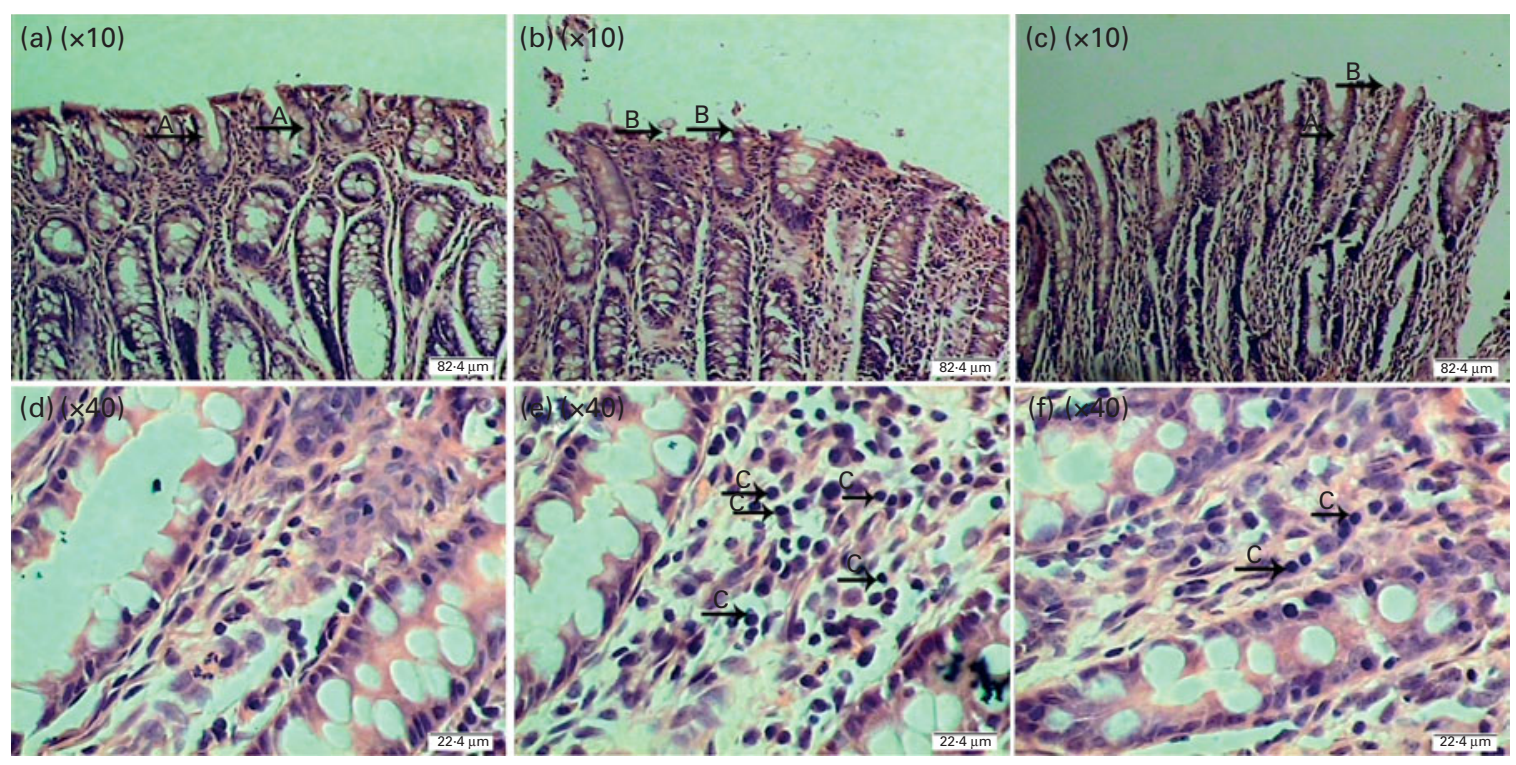

Fig. 1. Morphological changes in the colon of piglets after intrarectal administration of acetic acid (ACA). (a, d) Control group (non-challenged control): piglets fed the basal diet and intrarectally administered with saline; (b, e) ACA group (ACA-challenged control): piglets fed the basal diet and intrarectally administered with ACA, with colon injury characterised by the distortion of normal crypt architecture, loss of goblet cells, desquamation of epithelium and infiltration of lymphocytes; and $(\mathrm{c}, \mathrm{f}$ ) tributyrin (TBU) group (ACA challenge $+0.1 \%$ TBU supplementation): piglets fed the basal diet supplemented with $0.1 \%$ TBU and intrarectally administered with ACA, with histological changes being improved by TBU treatment. A, goblet cells; $\mathrm{B}$, the denuded epithelium; and $\mathrm{C}$, lymphocytes. 
Table 7. Effects of tributyrin (TBU) on amphiregulin $(A R)$, epidermal growth factor (EGF) and epidermal growth factor receptor (EGFR) mRNA levels in the colonic mucosa of piglets after the acetic acid challenge

(Mean values with their standard errors, $n 6$ )

\begin{tabular}{lccccc}
\hline Items & Control $^{*}$ & ACA & TBU & Pooled SEM & $P$ \\
\hline$A R$ & 1.00 & 1.24 & 1.23 & 0.201 & 0.436 \\
EGF & 1.00 & 1.39 & 1.40 & 0.168 & 0.433 \\
EGFR & $1.00^{\mathrm{b}}$ & $0.74^{\mathrm{a}}$ & $1.18^{\mathrm{b}}$ & 0.108 & 0.046 \\
\hline
\end{tabular}

ACA, acetic acid.

${ }_{\mathrm{a}, \mathrm{b}}$ Mean values within a row with unlike superscript letters were significantly different $(P<0.05)$.

${ }^{*}$ Non-challenged control: piglets fed the basal diet and intrarectally administered with saline.

†ACA-challenged control: piglets fed the basal diet and intrarectally administered with ACA.

$\mp$ ACA challenge $+0.1 \%$ TBU supplementation: piglets fed the basal diet supplemented with $0.1 \%$ TBU and intrarectally administered with ACA.

effects of dietary TBU supplementation on the attenuation of ACA-induced colitis in piglets. In the present study, we used a porcine model of colitis induced by administering ACA intrarectally to determine whether dietary TBU supplementation can alleviate intestinal injury and to elucidate the underlying mechanisms.

In the porcine model, the ACA challenge increased the number of leucocytes (including that of lymphocytes and neutrophils) and dietary TBU supplementation decreased the number of lymphocytes. These results indicate that ACA induced inflammation in the colon of piglets and TBU had an anti-inflammatory effect. Creatinine is a useful indicator of kidney function. The results of the present study indicate that the ACA challenge resulted in an increase in creatinine concentrations in the plasma, and this effect of ACA tended to be alleviated by dietary TBU supplementation. Similarly, Kim et $a l{ }^{(38)}$ reported that pigs had higher plasma creatinine concentrations after digestive disease. Elevated creatinine concentrations in the plasma signify renal dysfunction. When highly concentrated ACA is ingested, it can cause severe intravascular haemolysis, haemoglobinuria, acute hepatitis, coagulopathy, and acute gastrointestinal bleeding and acute renal failure ${ }^{(39,40)}$. It is of interest that we found dietary TBU supplementation to prevent the ACA-induced increase in creatinine concentrations in the plasma, suggesting that TBU may have a beneficial effect on the alleviation of renal dysfunction induced by ACA. The protection conferred by TBU was accompanied by a significant decrease in $\mathrm{PGE}_{2}$ generation and iNOS activity. Thus, intrarectal ACA administration readily resulted in systemic inflammation in piglets. This finding is consistent with an earlier report that ACA-induced colitis is associated with elevated concentrations of leukotriene $\mathrm{B} 4$ in the blood ${ }^{(13)}$. A decrease in iNOS activity in the TBU-treated piglets suggests that reduction in NO generation is one of the mechanisms responsible for the anti-inflammatory effect of TBU.

Ulcerative colitis is a chronic recurrent inflammatory bowel disease in which oxidative stress has been implicated ${ }^{(11)}$. In the colonic tissues of animals with ACA-induced colitis, myeloperoxidase activity and MDA concentrations are elevated, while reduced-glutathione concentrations as well as superoxide dismutase and CAT activities are decreased ${ }^{(11)}$. In the present study, dietary TBU supplementation suppressed the elevated MDA concentrations in the plasma of the ACA-challenged piglets. In addition, in the colonic mucosa of ACA piglets, MDA concentrations were elevated, while CAT activity was decreased, as reported previously for the rodent model $^{(11)}$. More importantly, dietary TBU supplementation suppressed the elevated MDA concentrations in the colonic mucosa of the ACA-challenged piglets. Thus, it appears that TBU exerts its antioxidant effects in piglets at both the systemic and intestinal levels. Oxidative stress and resultant tissue damage are the hallmarks of cell death. Of particular interest is the finding that ACA induced cell death through the activation of caspase- 3 and TBU attenuated the production of active caspase- 3 in the colon of the ACAchallenged piglets (Fig. 2). Caspase-3 is one of the key components of the apoptotic pathway in the small intestine $^{(21,41)}$. This protein is either partially or totally responsible for the proteolytic cleavage of many key 'death' proteins. These findings indicate a protective effect of TBU against ACA-induced enterocyte death and further support the conclusion that dietary TBU supplementation is effective at preventing intestinal injury and inflammatory disease.

Previous studies have demonstrated that plasma DAO is an indicator of the severity of mucosal injury ${ }^{(21,42,43)}$. In mammals, DAO is abundantly expressed in the duodenal and jejunal mucosa and, therefore, DAO activity is a noninvasive marker of alterations in intestinal mucosal function and structure ${ }^{(21,44)}$. Under certain circumstances, intestinal mucosal cells undergo necrosis and slough off into the
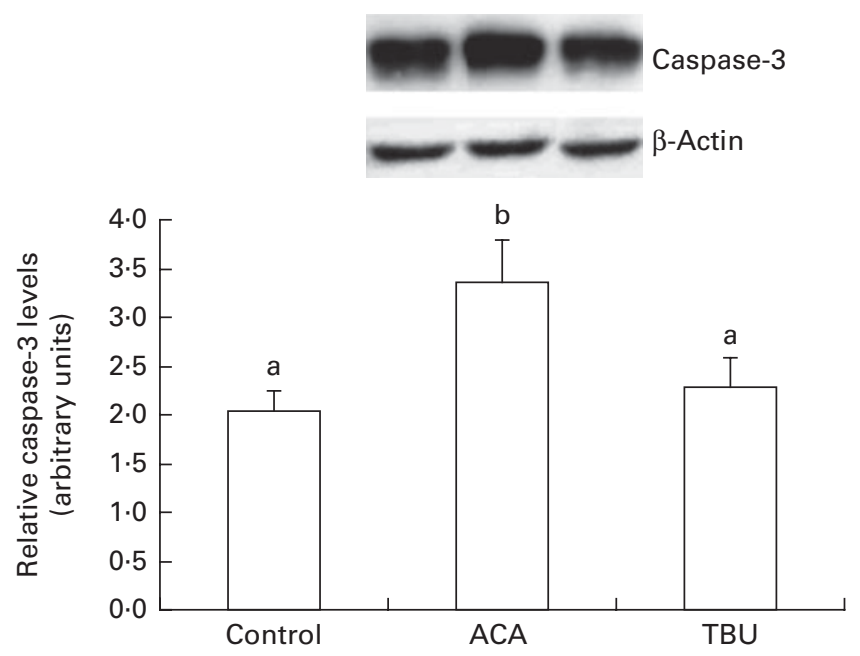

Fig. 2. Relative levels of caspase-3 protein in the colonic mucosa of piglets. Mucosal extracts ( $150 \mu \mathrm{g}$ protein/sample) were separated by $10 \%$ SDS-PAGE for the determination of caspase- 3 and $\beta$-actin levels. Values for caspase- 3 protein were normalised to those for $\beta$-actin. Values are means, with their standard errors represented by vertical bars $(n 6)$. Control group (nonchallenged control): piglets fed the basal diet and intrarectally administered with saline; acetic acid (ACA) group (ACA-challenged control): piglets fed the basal diet and intrarectally administered with $A C A$; and tributyrin (TBU) group (ACA challenge $+0.1 \%$ TBU supplementation): piglets fed the basal diet supplemented with $0.1 \%$ TBU and intrarectally administered with ACA. ${ }^{a, b}$ Mean values with unlike letters were significantly different $(P<0.05)$. 

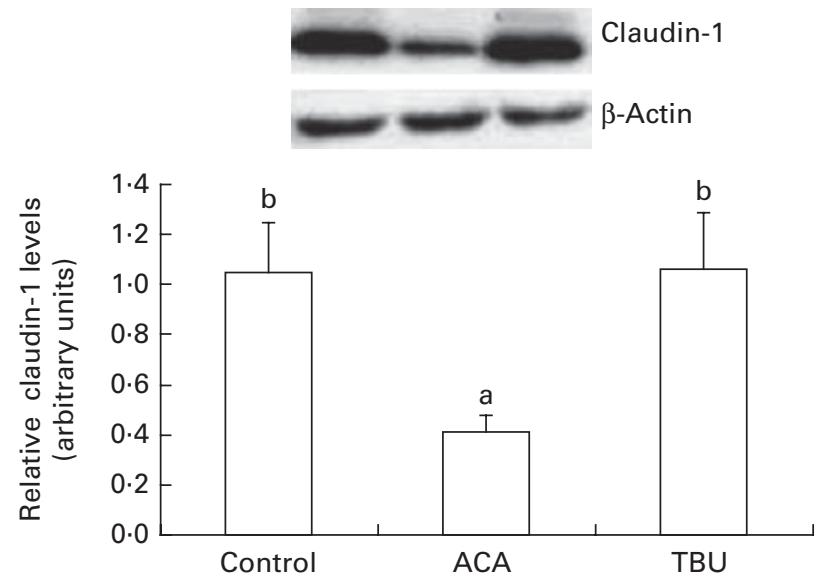

Fig. 3. Relative levels of claudin-1 protein in the colonic mucosa of piglets. Mucosal extracts $(60 \mu \mathrm{g}$ protein/sample) were separated by $12 \%$ SDS-PAGE for the determination of claudin-1 and $\beta$-actin levels. Values for relative claudin-1 were normalised to those for $\beta$-actin. Values are means, with their standard errors represented by vertical bars $(n 6)$. Control group (non-challenged control): piglets fed the basal diet and intrarectally administered with saline; acetic acid (ACA) group (ACA-challenged control): piglets fed the basal diet and intrarectally administered with ACA; tributyrin (TBU) group (ACA challenge $+0.1 \%$ TBU supplementation): piglets fed the basal diet supplemented with $0.1 \%$ TBU and intrarectally administered with ACA. ${ }^{\mathrm{a}, \mathrm{b}}$ Mean values with unlike letters were significantly different $(P<0.05)$.

intestinal lumen, leading to a decrease in intestinal mucosal DAO levels and an increase in circulating DAO levels ${ }^{(21,45)}$. In the present study, TBU decreased DAO activity in the plasma in response to ACA administration (Table 5), indicating that TBU supplementation may alleviate the colonic injury induced by intrarectal ACA administration. Furthermore, TBU supplementation resulted in the following: (1) an increased ratio of villus height:crypt depth in the ileum; (2) an increased number of goblet cells; (3) a decreased number of IEL; (4) decreased lymphocyte density in the colon. All these results indicate that TBU can affect the intestinal immune system and epithelial morphology. Our findings also support the notion that TBU beneficially alleviates the ACA-induced damage in the intestinal structure (Fig. 1). The integrity of the intestinal epithelium ensures its normal physiological function ${ }^{(22,46)}$. A damage to the mucosal epithelium can directly impair its integrity and the absorption of nutrients, thereby reducing the growth performance and compromising the health of pigs ${ }^{(21,46,47)}$. Accordingly, we observed that ACA reduced the abundance of claudin- 1 in the colonic mucosa of piglets, whereas dietary TBU supplementation increased the levels of claudin-1 in the colon of the ACA-challenged piglets (Fig. 3). It is possible that TBU affects intestinal functions by promoting tight-junction formation, as previous studies have demonstrated that the claudin family of proteins plays a critical role in epithelial permeability in a variety of tissues, including the gut ${ }^{(21,48,49)}$. Claudin-1 integrates diverse processes such as cell proliferation and mucosal integrity to affect intestinal function ${ }^{(21,50,51)}$.

Volatile fatty acids play a role in the modulation of the digestive process and can be supplied by direct feed supplementation. Butyric acid is produced by the bacterial fermentation of carbohydrates and amino acids in the lumen of the large intestine and serves as a primary source of energy for colonocytes as well as a strong mitosis promoter and a differentiation agent in the gastrointestinal tract in vivo ${ }^{(52,53)}$. It has been shown previously that TBU can improve the trophic status of the intestinal mucosa in the gut of piglets ${ }^{(2,52)}$. Taken together, these data indicate that TBU could enhance the intestinal barrier function and the ability of the intestine to absorb nutrients under inflammatory conditions. In the present study, however, dietary TBU supplementation partially alleviated the ACA-induced adverse changes in the measured intestinal variables. The dose effect of TBU was not investigated in the present study. Whether an insufficient dose of TBU is responsible for the partial alleviation effect remains to be determined.

Another significant finding from the present study is that dietary TBU supplementation increased the expression of the EGFR gene in the colonic mucosa (Table 7), which is consistent with our observations that TBU treatment resulted in reduced cell death (indicated by the decreased expression of caspase-3 protein) in the colonic mucosa of the ACAchallenged piglets. Similarly, results of previous studies have shown that EGF and its receptor (EGFR), which play important roles in the repair of the small-intestinal mucosa following damage ${ }^{(46,54,55)}$, are crucial for promoting enterocyte proliferation and migration as well as regeneration of the mucosal epithelium ${ }^{(31,56,57)}$. The beneficial outcomes of EGFR signalling include the stabilisation of the internal environment in the gut $^{(54,55)}$.

AR is a member of the EGF protein family ${ }^{(58)}$. It is an autocrine growth factor as well as a mitogen for many cell types, such as astrocytes, Schwann cells and fibroblasts. Interestingly, $\mathrm{AR}$ is related to EGF and transforming growth factor- $\alpha^{(48)}$. Through interaction with the EGF/transforming growth factor- $\alpha$ receptor, AR promotes the growth of normal epithelial cells and inhibits the proliferation of certain aggressive carcinoma cell lines ${ }^{(57,58)}$. In the present study, we observed that TBU did not affect $A R$ or $E G F$ mRNA levels, but increased EGFR expression in the colonic mucosa of the ACA-challenged piglets. Therefore, it is possible that TBU may alleviate colonic injury partly via EGFR signalling.

In conclusion, dietary supplementation with $0 \cdot 1 \% \mathrm{TBU}$ is beneficial for alleviating ulcerative colitis in piglets. Possible mechanisms for the actions of TBU may include the following: (1) reduction of oxidative stress (indicated by decreased production of MDA in the plasma); (2) alleviation of intestinal injury (indicated by alleviation of ACA-induced damage in the intestinal structure and decreased plasma DAO activity, decreased expression of caspase-3 protein and increased expression of claudin-1 protein in the colonic mucosa of the ACA-challenged piglets); (3) improvement of mucosal repair via EGF signalling (indicated by increases in EGFR expression in the colon). These findings may have important implications for treating colitis in humans and other animals.

\section{Acknowledgements}

The present study was jointly supported by the National Basic Research Program of China (no. 2012CB126305), the National 
Natural Science Foundation of China (no. 31372319), the Hubei Provincial Research and Development Program (no. 2010BB023), the Natural Science Foundation of Hubei Province (no. 2013CFA097, 2013CFB325, 2012FFB04805 and 2011CDA131), the National Research Initiative Competitive Grants from the Animal Growth and Nutrient Utilization Program (2008-35206-18764) of the USDA National Institute of Food and Agriculture and Texas AgriLife Research (H-82000). All these funding agencies had no role in the design and analysis of the study or in the writing of this article.

The authors' contributions are as follows: Y. H. designed the study and wrote the manuscript; L. W., D. Y., B. D., X. C., Q. W., H. Z. and Y. L. collected and analysed experimental results; Y. Y., J. G. and G. W. carried out the experiments and revised the paper. All authors contributed to data interpretation and approved the final version of the manuscript.

The authors declare that they have no conflicts of interest.

\section{References}

1. Lee DN, Wang CF, Cheng YH, et al. (2003) Dietary glutamine supplementation enhances weaned pigs mitogen-induced lymphocyte proliferation. Asian-Aust J Anim Sci 16, 1182-1187.

2. Hou YQ, Liu YL, Hu J, et al. (2006) Effects of lactitol and tributyrin on growth performance, small intestinal morphology and enzyme activity in weaned pigs. Asian-Aust J Anim Sci 19, $1470-1477$.

3. Gaschott T, Steinhilber D, Milovic V, et al. (2001) Tributyrin, a stable and rapidly absorbed prodrug of butyric acid, enhances antiproliferative effects of dihydroxycholecalciferol in human colon cancer cells. J Nutr 131, 1839-1843.

4. Roediger WE (1980) Role of anaerobic bacteria in the metabolic welfare of the colonic mucosa in man. Gut 21, 793-798.

5. von Engelhardt W, Bartels J, Kirschberger S, et al. (1998) Role of short-chain fatty acids in the hind gut. Vet $Q \mathbf{2 0}$, S52-S59.

6. Schröder O, Hess S, Caspary WF, et al. (1999) Mediation of differentiating effects of butyrate on the intestinal cell line Caco-2 by transforming growth factor-beta 1 . Eur J Nutr 38, 45-50.

7. Kuefer R, Hofer MD, Altug V, et al. (2004) Sodium butyrate and tributyrin induce in vivo growth inhibition and apoptosis in human prostate cancer. Br J Cancer 90, 535-541.

8. Leonel AJ, Teixeira LG, Oliveira RP, et al. (2013) Antioxidative and immunomodulatory effects of tributyrin supplementation on experimental colitis. Br J Nutr 109, 1396-1407.

9. Piva A, Grilli E, Fabbri L, et al. (2008) Intestinal metabolism of weaned piglets fed a typical United States or European diet with or without supplementation of tributyrin and lactitol. J Anim Sci 86, 2952-2961.

10. Usami M, Kishimoto K, Ohata A, et al. (2008) Butyrate and trichostatin A attenuate nuclear factor $\mathrm{\kappa B}$ activation and tumor necrosis factor $\alpha$ secretion and increase prostaglandin E2 secretion in human peripheral blood mononuclear cells. Nutr Res 28, 321-328.

11. Cetinkaya A, Bulbuloglu E, Kurutas EB, et al. (2005) Beneficial effects of $N$-acetylcysteine on acetic acid-induced colitis in rats. Tohoku J Exp Med 206, 131-139.

12. Sharon P \& Stenson WF (1985) Metabolism of arachidonic acid in acetic acid colitis in rats. Similarity to human inflammatory bowel diseas. Gastroenterology 88, 55-63.
13. Gulec B, Yasar M, Yildiz S, et al. (2004) Effect of hyperbaric oxygen on experimental acute distal colitis. Physiol Res $\mathbf{5 3}$ 493-500.

14. Fabia R, Willén R, Ar'Rajab A, et al. (1992) Acetic acidinduced colitis in the rat: a reproducible experimental model for acute ulcerative colitis. Eur Surg Res 24, 211-225.

15. Yamada Y, Marshall S, Specian RD, et al. (1992) A comparative analysis of two models of colitis in rats. Gastroenterology 102, 1524-1534.

16. Myers BS, Dempsey DT, Yasar S, et al. (1997) Acute experimental distal colitis alters colonic transit in rats. J Surg Res 69, 107-112.

17. Wang QJ, Hou YQ, Yi D, et al. (2013) Protective effects of $\mathrm{N}$-acetylcysteine on acetic acid-induced colitis in a porcine model. BMC Gastroenterol 13, 133.

18. Piva A, Morlacchini M, Casadei G, et al. (2002) Sodium butyrate improves growth performance of weaned piglets during the first period after weaning. Ital J Anim Sci 1, 35-41.

19. Lu JJ, Zou XT \& Wang YM (2008) Effects of sodium butyrate on the growth performance, intestinal microflora and morphology of weanling pigs. J Anim Feed Sci 17, 568-578.

20. Hou Y, Yao K, Wang L, et al. (2011) Effects of $\alpha$-ketoglutarate on energy status in the intestinal mucosa of weaned piglets chronically challenged with lipopolysaccharide. Br J Nutr 106, 357-363.

21. Hou Y, Wang L, Zhang W, et al. (2012) Protective effects of $\mathrm{N}$-acetylcysteine on intestinal functions of piglets challenged with lipopolysaccharide. Amino Acids 43, 1233-1242.

22. Hou Y, Wang L, Ding B, et al. (2010) Dietary $\alpha$-ketoglutarate supplementation ameliorates intestinal injury in lipopolysaccharide-challenged piglets. Amino Acids 39, 555-564.

23. Yi D, Hou YQ, Wang L, et al. (2014) Dietary $N$-acetylcysteine supplementation alleviates liver injury in lipopolysaccharidechallenged piglets. Br J Nutr 111, 46-54.

24. Li P, Kim SW, Li X, et al. (2009) Dietary supplementation with cholesterol and docosahexaenoic acid affects concentrations of amino acids in tissues of young pigs. Amino Acids 37, 709-716.

25. Wang J, Chen L, Li D, et al. (2008) Intrauterine growth restriction affects the proteomes of the small intestine, liver and skeletal muscle in newborn pigs. J Nutr 138, 60-66.

26. Nofrarías M, Manzanilla EG, Pujols J, et al. (2006) Effects of spray-dried porcine plasma and plant extracts on intestinal morphology and on leukocyte cell subsets of weaned pigs. J Anim Sci 84, 2735-2742.

27. Wang X, Ou D, Yin J, et al. (2009) Proteomic analysis reveals altered expression of proteins related to glutathione metabolism and apoptosis in the small intestine of zinc oxide-supplemented piglets. Amino Acids 37, 209-218.

28. Han J, Liu YL, Fan W, et al. (2009) Dietary L-arginine supplementation alleviates immunosuppression induced by cyclophosphamide in weaned pigs. Amino Acids 37, 643-651.

29. Hosoda N, Nishi M, Nakagawa M, et al. (1989) Structural and functional alterations in the gut of parenterally or enterally fed rats. J Surg Res 47, 129-133.

30. Luk GD, Bayless TM \& Baylin SB (1980) Diamine oxidase (histaminase). A circulating marker for rat intestinal mucosal maturation and integrity. J Clin Invest 66, 66-70.

31. Hou Y, Wang L, Yi D, et al. (2013) $N$-Acetylcysteine reduces inflammation in the small intestine by regulating redox, EGF and TLR4 signaling. Amino Acids 45, 513-522.

32. Luna LG (1968) Manual of Histologic Staining Methods of the Armed Forces Institute of Pathology, 3rd ed. New York, NY: McGraw-Hill Book Company. 
33. Fu WJ, Stromberg AJ, Viele K, et al. (2012) Statistics and bioinformatics in nutritional sciences: analysis of complex data in the era of systems biology. $J$ Nutr Biochem 21, 561-572.

34. Nygard A, Jørgensen CB, Cirera S, et al. (2007) Selection of reference genes for gene expression studies in pig tissues using SYBR green qPCR. BMC Mol Biol 8, 67.

35. Vandesompele J, De Preter K, Pattyn F, et al. (2002) Accurate normalization of real-time quantitative RT-PCR data by geometric averaging of multiple internal control genes. Genome Biol 3, research0034.1-0034.11.

36. Wei J, Carroll RJ, Harden KK, et al. (2012) Comparisons of treatment means when factors do not interact in two-factorial studies. Amino Acids 42, 2031-2035.

37. Nieto N, Torres MI, Fernández MI, et al. (2000) Experimental ulcerative colitis impairs antioxidant defense system in rat intestine. Dig Dis Sci 45, 1820-1827.

38. Kim JC, Mullan BP, Hampson DJ, et al. (2008) Addition of oat hulls to an extruded rice-based diet for weaner pigs ameliorates the incidence of diarrhoea and reduces indices of protein fermentation in the gastrointestinal tract. $\mathrm{BrJ} \mathrm{Nutr}$ 99, 1217-1225.

39. Chibishev A, Sikole A, Pereska Z, et al. (2013) Severe renal function impairment in adult patients acutely poisoned with concentrated acetic acid. Arb Hig Rada Toksikol 64, $153-158$.

40. Tong GMW, Mak SK, Wong PN, et al. (2000) Successful treatment of oral acetic acid poisoning with plasmapheresis. Hong Kong J Nephrol 2, 110-112.

41. Tan B, Yin Y, Kong X, et al. (2010) L-Arginine stimulates proliferation and prevents endotoxin-induced death of intestinal cells. Amino Acids 38, 1227-1235.

42. Hou Y, Wang L, Ding B, et al. (2011) Alpha-ketoglutarate and intestinal function. Front Biosci 16, 1186-1196.

43. Luk GD, Bayless TM \& Baylin SB (1983) Plasma postheparin diamine oxidase. Sensitive provocative test for quantitating length of acute intestinal mucosal injury in the rat. $J$ Clin Invest 71, 1308-1315.

44. Li JY, Yu Y, Hao J, et al. (1996) Determination of diamine oxidase activity in intestinal tissue and blood using spectrophotometry. Amino Acids Biotic Resour 18, 28-30.

45. Li JY, Lu Y, Hu S, et al. (2002) Preventive effect of glutamine on intestinal barrier dysfunction induced by severe trauma. World J Gastroenterol 8, 168-171.

46. Liu F, Yin J, Du M, et al. (2009) Heat-stress-induced damage to porcine small intestinal epithelium associated with downregulation of epithelial growth factor signaling. $J$ Anim Sci 87, 1941-1949.

47. Boudry G, Péron V, Le Huërou-Luron I, et al. (2004) Weaning induces both transient and long-lasting modifications of absorptive, secretory, and barrier properties of piglet intestine. J Nutr 134, 2256-2262.

48. Howe KL, Reardon C, Wang A, et al. (2005) Transforming growth factor- $\beta$ regulation of epithelial tight junction proteins enhances barrier function and blocks enterohemorrhagic Escherichia coli O157: h7-induced increased permeability. Am J Pathol 167, 1587-1597.

49. Tsukita S \& Furuse M (2000) The structure and function of claudins, cell adhesion molecules at tight junctions. Ann $N$ $Y$ Acad Sci 915, 129-135.

50. Rhoads JM \& Wu G (2009) Glutamine, arginine, and leucine signaling in the intestine. Amino Acids 37, 111-122.

51. Schneeberger EE \& Lynch RD (2004) The tight junction: a multifunctional complex. Am J Physiol Cell Physiol 286, C1213-C1228.

52. Piva A, Prandini A, Fiorentini L, et al. (2002) Tributyrin and lactitol synergistically enhanced the trophic status of the intestinal mucosa and reduced histamine levels in the gut of nursery pigs. J Anim Sci 80, 670-680.

53. Salminen S, Bouley C, Boutron-Ruault MC, et al. (1998) Functional food science and gastrointestinal physiology and function. Br J Nutr 80, S147-S171.

54. Helmrath MA, Shin CE \& Erwin CR (1998) Intestinal adaptation is enhanced by epidermal growth factor independent of increased ileal epidermal growth factor receptor expression. J Pediatr Surg 33, 980-985.

55. Nair RR, Warner BB \& Warner BW (2008) Role of epidermal growth factor and other growth factors in the prevention of necrotizing enterocolitis. Semin Perinatol 32, 107-113.

56. Engler JA, Gupta A \& Li L (1999) Inhibition of DNA synthesis in Caco-2 cells by oxidative stress amelioration by epidermal growth factor. Dig Dis Sci 44, 1902-1909.

57. Ryan CK, Miller JH, Seydel AS, et al. (1997) Epidermal growth factor and neurotensin induce microvillus hypertrophy following massive enterectomy. J Gastrointest Surg 1, 467-473.

58. Ciarloni L, Mallepell S \& Brisken C (2007) Amphiregulin is an essential mediator of estrogen receptor $\alpha$ function in mammary gland development. Proc Natl Acad Sci U S A 104, $5455-5460$ 